\title{
Epidemiological Aspects of Theileriosis in Cattle in and around Patna, Bihar, India
}

\author{
Shashi Kala ${ }^{1 *}$, Bhawesh Gopal Deo ${ }^{2}$ and Nikee Kumari ${ }^{1}$ \\ ${ }^{1}$ (Parasitology Section), Institute of Animal Health and Production, Bihar, Patna, India \\ ${ }^{2}$ (Parasitology), Institute of Animal Health and Production, Bihar, Patna, India
}

*Corresponding author

\begin{tabular}{|l|}
\hline K e y w o r d s \\
Theileriosis, \\
Incidence, Blood \\
smear, Season, Breed, \\
Age, Sex, Cattle, \\
Patna
\end{tabular}

\section{Introduction}

Theileriosis is a major constraint to livestock production and food securities in many developing countries. Bovine theileriosis is a haemoprotozoan disease caused by parasites of genus Theileria belonging to Family Theileridae, which are round ovoid rod like or irregular shaped organism found in lymphocytes, histiocytes and erythrocytes (Soulsby, 1982). There are different species of Theileria, among which Theileria annulata and Theileria parva are considered as most pathogenic species causing lymphoproliferative diseases. A severe form of the disease called Bovine Tropical theileriosis is caused by Theileria annulata and transmitted by Ixodid ticks of Hyalomma 
spp. These are usually two host ticks because the larva moult to nymph on the same host, nymph detaches and drops off on the ground to moult into an adult and seek a new host. The hot and humid climate acts as highly favourable criteria for the development and survival of tick vector and is a constant source of infection to susceptible animals (Singh et al., 2017 and Kohli et al., 2014). Ticks are voracious blood sucking obligate ectoparasites of cattle (Bishop et al., 2004). Blood loss due to heavy tick infestation impoverishes hosts and cattle may remain weak and stunted. Almost $80 \%$ of the cattle are exposed to tick infestation worldwide (Anim et al., 2013).

Usually tick preferred thin and short hair skin for infestation because mouth part can easily penetrate the vascular region for feeding (Sajid, 2007). Most of the animals suffered during monsoon month, which might be due to more number of ticks in monsoon which were developing during summer months (Ananda et al., 2009). Previously the disease has been reported from different states by various workers in several years, Odisha (Singh et al., 2017, Acharya et al., 2017 and Acharya et al., 2016), Punjab (Kumar et al., 2015), Hariyana (Chaudhari et al., 2013), Gujarat (Vahora et al., 2012) and North Bangalore (Ananda et al., 2009).

Dairy animals, especially bovines, which are bearing production stress along with other diseases, are potential viable host to the infections. Bovine theileriosis is a tick-borne diseases cause substantial losses to the livestock industry throughout the world (Ananda et al., 2009) as these have got a serious economic impact due to obvious reason of death, decreased productivity, lowered working efficiency (Uilenberg, 1995), increased cost for control measures (Makala et $a l$. , 2003) and limited introduction of genetically improved cattle in an area (Radostits et al., 1994) and is of great economic importance in Asia and has always been a formidable barrier to the survival of exotic and cross bred cattle in India. It causes significant morbidity and mortality in cattle and buffaloes. Devendra, (1995) reported the annual loss of US \$ 800 million due to tropical theileriosis in India.

Most common symptoms of bovine theileriosis are anorexia, pyrexia, conjunctival petechia, swollen lymph nodes, weight loss, weakness, coughing, nasal discharge, and diarrhoea. Tentative diagnosis in field is mainly based on clinical signs and tick infestation on the infected animals. However confirmatory diagnosis based on microscopic examination of Giemsa stained thin blood smears. Many animals die and undergo a long period of convalescence entailing loss of milk and meat production. The mortality rate can be reduced with early diagnosis and effective treatment.

The present investigation was carried out to record the incidence of theileriosis along with other epidemiological parameters of bovine theileriosis in and around Patna, Bihar

\section{Materials and Methods}

\section{Samples collection}

During the period from May 2015 to April 2016, a total of 937 blood samples of cattle were received at Parasitology Section, Institute of Animal Health and Production, Bihar, Patna with clinical manifestation of high rise of temperature, enlargement of lymph nodes, anaemia, anorexia, weakness, nasal discharge, reduced milk yield and history of tick infestation. Mostly the samples were referred by field veterinarians. The samples received were generally of female cattle of all ages. It includes both indigenous and crossbred animals. The blood samples were brought in vial containing EDTA. 


\section{Smear preparation}

Thin blood smears were prepared and were air dried, fixed with methanol, stained with Giemsa stain and examined under the oil immersion lens (100X) of microscope (Zafar et al., 2006; Qayyum et al., 2010). The parasites were identified according to the characters described by Soulsby (1982). Blood smears were examined carefully (Fig. 2) and even the presence of single piroplasm was considered positive for Theileria spp. A total 937 cases were screened and out of which $291(31.05 \%)$ cases were found positive for theileriosis.

\section{Microscopic examination}

The diagnosis of Theileria infection is based on clinical findings and microscopic examination of Giemsa stained thin blood and lymph node smears in acute cases. Giemsa staining technique is frequently used for detection of parasite as it is comparatively inexpensive. However, expertise in microscopic detection of piroplasm is required in subclinical or chronic infection because parasitemia is often extremely low and may otherwise miss (Maharana et al., 2016). Subclinical infection in cattle with Theileria annulata in endemic regions produces chronic carrier state and serves as source of infection for ticks.

\section{Data analysis}

On the basis of blood smear examination, the positive cases of theileriosis were spreaded as breed, age, sex and season wise. To record age wise incidence, cases were distributed in three age groups viz., below 6 months, 6 months to 2 years and above 2 years. Further to study the seasonal incidence of the disease the data were analysed as per season viz., summer (MarchJune), rainy (July-November) and winter (December-February). An important feature of the retreating monsoon season in Bihar is the invasion of tropical cyclones originating in the Bay of Bengal at about $12^{\circ} \mathrm{N}$ latitude. Bihar is also influenced by the typhoons originating in South China Sea. The maximum frequency of the tropical cyclones in Bihar is during September-November especially during the asterism called hathiya. Data obtained were compiled and tabulated for frequency and finally converted into percentage to draw inferences. Chi-square test was used to see significant differences $(\mathrm{P}<0.01)$ in parasitic infections among breed, age, sex and season (Maharana et al., 2016).

\section{Results and Discussion}

The analysis of data revealed that out of 937 blood samples, $291(31.05 \%)$ samples were found positive for theileriosis.

\section{Breed wise incidence}

From Table 1 (Fig. 1b), it is evident the incidence of theileriosis was higher in cross breed $(63.57 \%)$ than indigenous $(36.43 \%)$. The value of $x^{2}$ d.f (21.36) revealed highly significant $(<0.01)$ difference in the incidence pattern of bovine theileriosis on the susceptibility of indigenous and crossbred cattle.

\section{Age wise incidence}

The data shows (Table 2) that the animals above 2 years of age were more susceptible $(92.78 \%)$ than the animals of 6 months to 2 years of the age (7.22\%). However the evidence of theileriosis was not found in calves below 6 months of age.

\section{Sex wise incidence}

From Table 2, it is evident that the incidence of the disease was higher in female $(97.94 \%)$ than in male $(2.06 \%)$. 


\section{Season wise incidence}

From Table 3 (Fig. 1a), the analysis of different seasons revealed significantly $(<0.01)$ higher incidence of theileriosis during rainy season $129(44.33 \%)$ and minimum during winter season 61(20.96\%). The incidence of theileriosis during summer season was found $101(34.71 \%)$.

The present study is focussed on haemoprotozoan disease theileriosis, a major constraint to livestock production and its prevalence in and around Patna, Bihar. Theileriosis is a fatal parasitic tick-borne disease. Majority of cases were manifesting common clinical sign viz. anorexia, pyrexia, pale conjunctival mucous membrane, enlargement of prescapular and prefemoral lymph nodes, nasal discharge, coughing, grinding of teeth, diarrhoea, respiratory distress, lacrimation, cornial opacity and anaemia.

The study was carried for a year from May 2015 to April 2016 by using Giemsa staining technique (Fig. 2). Similar clinical sign in theileriosis affected animals were reported by many workers (Singh et al., 2017; Soulsby, 1982; Singh et al., 2001; Masare, et al., 2009; Radostits et al., 2010 and Khan et al., 2011). The prevalence of theileriosis depend on geographical region and several other factors like density, climatic conditions, age, sex, management practices and immunity either passive or active (Magona et al., 2011 and Gul et al., 2015).

Breed wise incidence of theileriosis were significantly $(<0.01)$ higher in crossbred $(63.57 \%)$ than indigenous cattle $(36.43 \%)$. This might be due to higher susceptibility of crossbred animal to the disease. The results of the present investigation on breed wise susceptibility are in close agreement with the finding of Singh et al., (2001), Rakha and
Sharma (2003), Qayuum et al., (2010), Panda et al., (2011), Kohli et al., (2014), Velusamy et al., (2014), Acharya et al., (2016), who reported higher incidence of theileriosis in crossbred than the indigenous breed.

The present study is in accordance with Ananda et al., (2009), who observed breed wise susceptibility in crossbred cattle of Bangalore North. However, Maharana et al., (2016) reported breed wise higher infection rate in non-descript cattle $(42.46 \%)$ than pure breed $(29.62 \%)$. The prevalence is influenced by cattle breed as cattle usually differ in tick resistance and innate susceptibility to infection (Muhammad et al., 2008 and Gul et al., 2015).

Age wise investigation showed the higher incidence of theileriosis in animals above 2 years of age (92.78\%) than the animals between 6 months to 2 years of age (7.22\%). However the incidence of theileriosis was not observed in calves below 6 months of age, this might be due to passive immunity from mother. The present observations are in close agreement with Singh et al., (2017), who recorded more incidence in older calves of 712 months of the age than younger calves and also reported that farmers prefers to give anti theilerial treatment to calves without going for blood examination because calves need a smaller dose due to less body weight and the drug acts as both preventive and curative purpose. These findings were in contrary to finding of previous worker Masare et al., (2009) who reported higher incidence of theileriosis in calves below 2 months of age (73.33\%) than older ones (above 2 month and up to 12 months age) presented to TVCSC, COVAS, Udgir, Maharashtra. However Maharana et al., (2016) reported, the risk of overall prevalence of haemoprotozoan infection was significantly higher in older (more than 5 years) and lower in adult (1- 5 years) in comparison to young cattle (below 1 year). 
Table.1 Breed wise distribution of theileriosis in cattle in and around Patna

\begin{tabular}{|c|c|c|c|}
\hline Breed & Frequency & Percentage & Calculated $\chi^{2}{ }_{\mathbf{1}} \mathbf{d . f}$ \\
\hline Indigenous & 106 & 36.43 & \multirow{2}{*}{$21.36^{* *}$} \\
\hline Crossbred & 185 & 63.57 & \\
\hline Total & 291 & 100 & \\
\hline
\end{tabular}

**Significant at $<0.01$

Table.2 Age and sex wise distribution of theileriosis in cattle in and around Patna

\begin{tabular}{|c|c|c|c|}
\hline Age Group & Male & Female & Total \\
\hline Below 6 months & 0 & 0 & 0 \\
\hline 6 months-2 years & $4(1.37 \%)$ & $17(5.84 \%)$ & $21(7.22 \%)$ \\
\hline Above 2 years & $2(0.69 \%)$ & $268(92.10 \%)$ & $270(92.78 \%)$ \\
\hline Total & $6(2.06 \%)$ & $285(97.94 \%)$ & $291(100 \%)$ \\
\hline
\end{tabular}

Table.3 Season wise distribution of theileriosis in cattle in and around Patna

\begin{tabular}{|c|}
\hline Season \\
\hline Rainy \\
\hline Winter \\
\hline Summer \\
\hline Total \\
\hline
\end{tabular}

\begin{tabular}{|c|c|c|}
\hline Frequency & Percentage & Calculated $\chi_{2}^{2} \mathbf{d . f}$ \\
\hline 129 & 44.33 & \\
\hline 61 & 20.96 & $24.07 * *$ \\
\hline 101 & 34.71 & \\
\hline 291 & 100 & \\
\hline
\end{tabular}

$* *$ Significant at $<0.01$

Fig.1 (a) Season and (b) Breed wise incidence of theileriosis in cattle in and around Patna
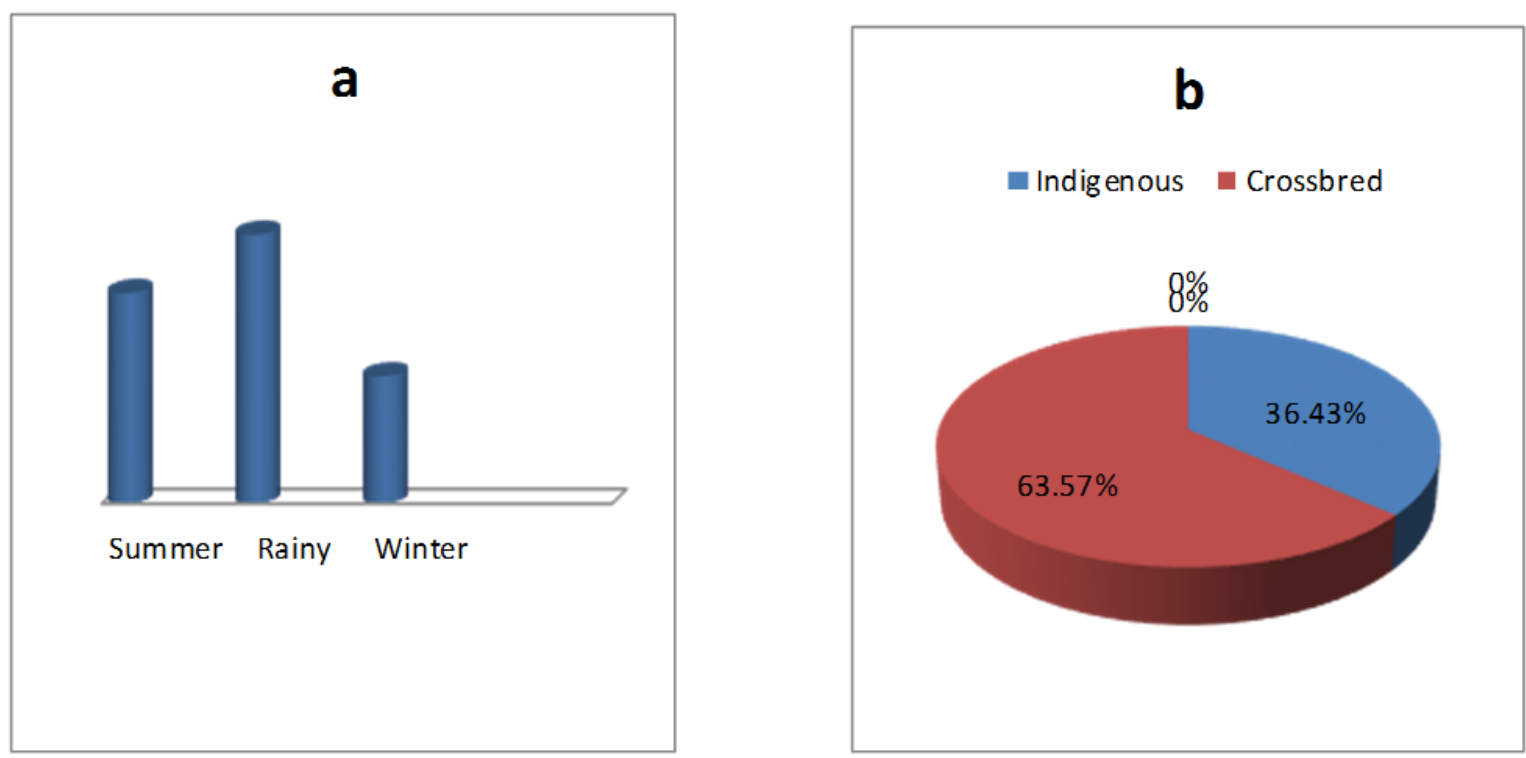
Fig.2 Giemsa stained blood smear showing piroplasm of Theileria parasites (100 X)

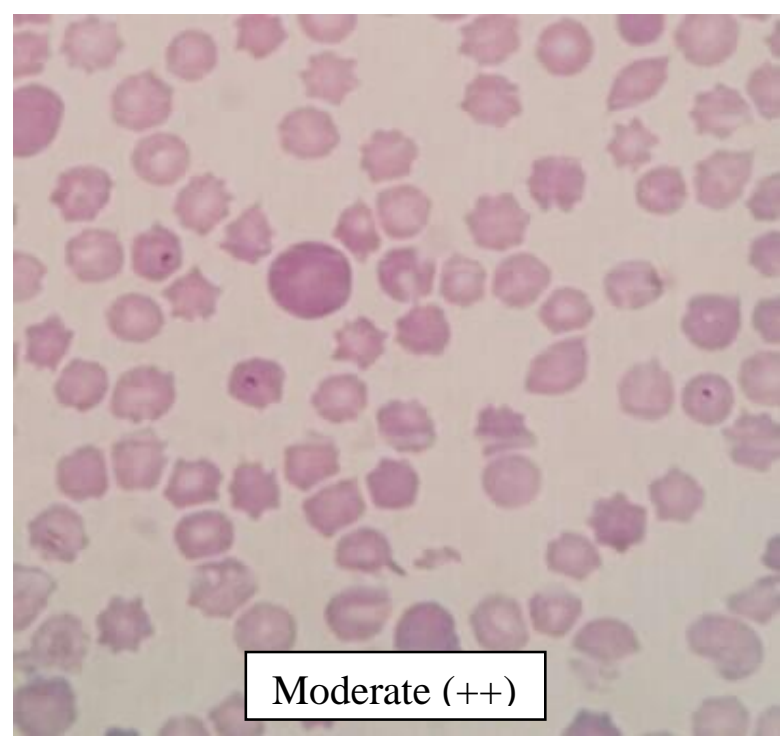

Inverse age resistance and stronger passively acquired immunity might be due to the contributing factors behind the lower incidence of haemoprotozoan parasites in younger age group of animals (Maharana et al., (2016). While, Khan et al., (2017) reported higher prevalence in cattle above 5 years $(29.90 \%)$ followed by calves below 1 year $(27.15 \%)$ and in cattle $1-5$ years of age $(23.06 \%)$.

Sex wise incidence was recorded higher in female $(97.94 \%)$ than male $(2.06 \%)$. This might be due to less market value of male crossbred animal and also farmers are interested in raising female calves as replacement stock. Due to introduction of artificial insemination technology in livestock production, the owners are not interested for rearing and spending on male calves. As a result of which more number of blood samples from female cattle were presented for diagnosis. Similar observations were also recorded by Panda et al., (2011) and Khan et al., (2017), who reported higher prevalence of theileriosis in females than males. However, Maharana et al., (2016) reported higher incidence of haemoprotozoan parasite

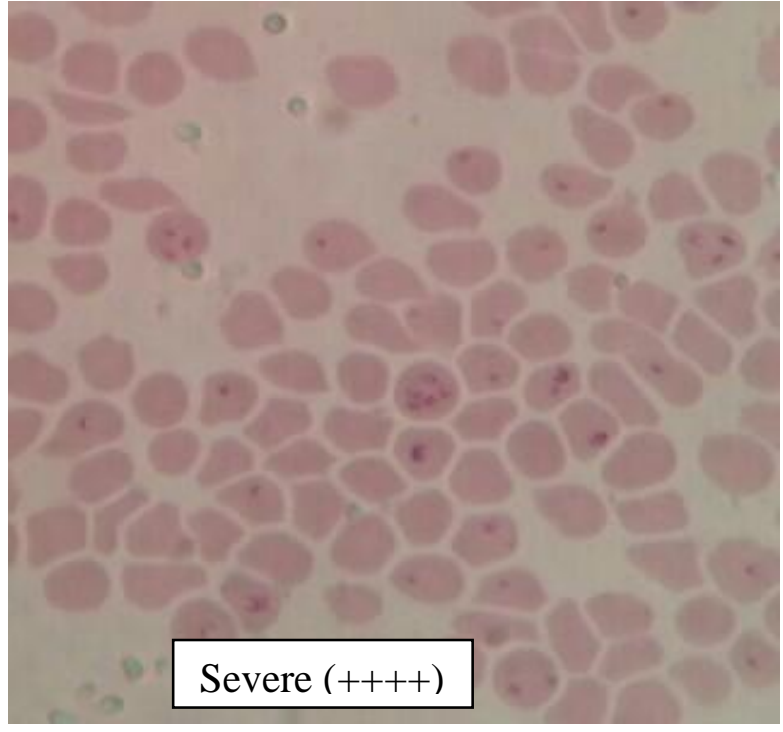

infection in female cattle than male but did not differ significantly owing to common managemental practices being adopted for both the sexes and also reported higher prevalence in female might be due to hormonal disturbances which penetrate it to weakened immune system.

Seasonal investigation on bovine theileriosis revealed that the season played a significant $(<0.01)$ role on the incidence of bovine theileriosis. The highest incidence of the disease was observed in rainy season $(44.33 \%)$ followed by summer season (34.71\%) and winter season (20.96\%), this might be due to abundance of tick during rainy season which were developed during summer months. The observation are in agreement with Kohli et al., (2014), who reported that theileriosis is most prevalent in rainy season and minimum in winter season. Our results are also in close agreement with a study, in which Vahora et al., (2012) and Bhatnagar et al., (2015) recorded higher incidence of theileriosis during monsoon. However Velusamy et al., (2014) recorded significantly high prevalence of theileriosis during summer followed by moderate in 
monsoon and less in fair seasons. These differences are might be due to climatic changes, because high temperature and humidity is ideal for survival and breeding of ticks. Similarly, Chaudhri et al., (2013) recorded higher infection in summer and rainy season $(9.2 \%$ and $1.1 \%)$ than in winter, correlated to the high activity of their tick vectors during summer and rainy seasons.

The increased incidence in rainy season was indicative of seasonal occurrence of the disease due to the presence of vectors. The highest abundance of tick was reported in the month of July (Sajid et al., 2007), whereas Hyalomma spp. of tick is most abundant in June (Durrani et al., 2008). By using Giemsa staining method, Khan et al., (2017) reported over all $14.32 \%$ prevalence of theileriosis in cattle from the period of March to May.

On the basis of blood smear examination it was concluded, the incidence of bovine theileriosis was significantly higher in rainy season especially in crossbred cattle might be due to abundance of vectors developing during summer season. Therefore, in order to reduce the incidence of theileriosis there is a need for further investigation by using molecular diagnostic technique like PCR for the diagnosis of carriers of the theileriosis and appropriate tick eradication programmes may be adopted.

\section{References}

Acharya AP, Panda SK, Das RK, Panda MR, Das S, Gupta AR. Prevalence of Bovine tropical theileriosis in cattle reared in and around Bhubaneswar. Indian Journal of Veterinary Medicine. 2016; 36(1): 20-22.

Acharya AP, Panda SK, Prusty BK. Diagnosis and confirmation of Theileria annulata infection in cattle in Odisha, India.
Journal of Entomology and Zoology Studies. 2017; 5(4):1543-1546.

Ananda, K.J., D'Souza, P.E., Puttalakshmamma, G.C. 2009. Prevalence of Haemoprotozoan diseases in crossbred cattle in Bangalore north. Vet. World, 2(1): 1516.

Anim, J., Ali, Z., Maqbool, A., Muhammad, K., Khan, M.S., Younis, M. 2013. Prevalence of Theileria annulata infected hard ticks of cattle and buffalo in Punjab, Pakistan. Pak. Veter. J., 23(1): 20-26.

Bhatnagar, C.S., Bhardawaj, B, Sharma, D.K. and Meena, S.K. (2015). Incidence of Haemoprotozoan diseases in cattle in Southern Rajasthan, India. Int. J. Curr. Microbiol. App. Sci. 4: 509-514.

Bishop, R., Musoke, A., Morzaria, S., Gardner, M., Nene, V. 2004. "Theileria: Intracellular protozoan parasites of wild and domestic ruminants transmitted by Ixodid ticks". Parasitology, 129(7): S271-S283.

Chaudhuri SS, Bisla RS, Bhanot V, Singh H. Prevalence of hemprotozoan infections in pyretic dairy animals of eastern Haryana. Indian Journal of Animal Research. 2013; 47(4):344-347.

Devendra, C. (1995): In Global Agenda for Livestock Research, EDS, ILRI, Nairobi., pp. 41-48.

Durrani, A.Z., Shakoori, A.R., Kamal, N. 2008. Bionomics of Hyalomma ticks in three districts of Punjab, Pakistan. $J$. Anim. Plant Sci., 18(1): 20-23.

Gul N., Ayaz S., Gul I., Adnan M., Shams S. and Akbar N. Tropical theileriosis and east coast fever in cattle: present, past and future perspective. Int. J. Microbio. App. Sci. (2015) 4(8):1000-1080.

Khan A., Ashfaq K., Din I., Haq R., Jamil M., Ullah B.,Ullah S., Rehman H., Ullah F., 2017.Bovine theileriosis: prevalence, estimation of haematological profile and chemotherapy in cattle in Dera Ismail 
Khan, Khyber Pakhtunkhwa Province, Pakistan. Ameri. Sci. Res. J. for Eng. Tech. and Sci. (ASRJETS), 32(1): 8-17

Khan IA, Khan A, Hussain A, Riaz A, Aziz A. Hematobiochemical alterations in cross bred cattle affected with bovine theileriosis in semi- arid zone. Pakisthan Veterinary Journal. 2011; 31(2):137140.

Kohli, S., Atheya, U.K., Thapliyal, A. 2014. Prevalence of theileriosis in cross-bred cattle: its detection through blood smear examination and polymerase chain reaction in Dehradun district, Uttarakhand, India. Veter. World, 7(3): 168-171.

Kumar V, Kaur P, Pal Heigo, Kumar P, Sharma H, Wadhawan VM. Theileriosis in calves and its successful therapeutic management. Scholars Journal of Agriculture and Veterinary Science. 2015; 2(3A):180-181.

Magona, J.W., Walubengo, J., Olaho-Mukani, W., Jonsson, N.N., Welburn, S.W. and Eisler, M.C. (2011) Spatial variation of tick abundance and seroconversion rates of indigenous cattle to Anaplasma marginale, Babesia bigemina and Therileria parva infections in Uganda., 55: 203-213.

Maharana B.R., Kumar B., Prasad A., Patbandhan T.K., Sudhakar N.R., Joseph J.P. and Patel B.R., 2016. Prevalence and assessment of risk factors for haemoprotozoan infections in cattle and buffaloes of South -West Gujarat, India. Indian J. Anim. Res., 50(5); 733-739.

Maharana B.R., Tewari A.K., Saravanan B.C., Sudhakar N.R., 2016. Important hemoprotozoan diseases of livestock: Challenges in current diagnostics and therapeutics: An update, Veterinary World, 9(5): 487-495.

Makala, L.H., Mangani, P., Fujisaki, K., Nagasawa, H. 2003. The current status of major tick borne diseases in Zambia. Vet.Res., 34: 2745.

Masare PS, Bhikane AU, Syed AM, Ghoke SS, Awaz KB. Epidemiological and Clinico-therapeutic studies on theileriosis calves. Intas Polivet. 2009; 10(11):289-292.

Muhammad, G., Naureen, A., Firyal, S., Saqib, M. 2008. Tick control strategies in dairy production medicine. Pak. Veter. J., 28(1): 43-50.

Panda SK, Sahu B, Rajeev Ranjan, Acharya AP, Rath SK. Prevalence and clinicopathological study of theileriosis in bovine in coastal areas of Orissa. Indian Journal Veterinary Pathology. 2011; 35(2):128-132.

Qayyum, A., Farooq, U., Samad, H.A., Chauhdry, H.R. 2010. Prevalence, clinicotherapeutic and prophylactic studies on theileriosis in district Sahiwal (Pakistan). J. Anim. Plant Sci., 20(4): 266-270.

Radostits OM, Gay CC, Hinchcliff KW, Constable PD. Veterinary Medicine, 9th Edn, Saunders Publishers Ltd, London, 2010, 1530-31.

Radostits, O.M., Blood, D.C., Gay, C.C. 1994.Veterinary medicine, A text book of the disease, sheep, goats, pigs and horse, $8^{\text {th }}$ edn. ELBS, Baillier, London.

Rakha and Sharma. Current Epidemiological status of Bovine tropical theileriosis in Haryan, India. Intas Polyvet. 2003; 4(1):15-22.

Sajid, M.S. 2007. Epidemiology, acaricidal resistance of tick population infesting domestic ruminants, Ph.D Thesis, University of Agriculture, Faisalabad, Pakistan.

Singh J., Acharya AP., Panda SK., Patra BK., and Behra K., 2017. Theilerial infection in young bovine calves in Odisha, India. J. Ent. and Zoology Studies., 5(5): 1201-1204. 
Singh, A., Singh, J., Grewal, A.S., Brar, R.S. 2001. Studies on some blood parameters of crossbred calves with experimental Theileria annulata infections. Veter. Res. Commun., 25: 289-300.

Soulsby, E.J.L. 1982. Helminths, arthropods and protozoan of domesticated animals, $m 7^{\text {th }}$ edn., Bailiere Tindall and Cassell Ltd., London.

Uilenberg, G. 1995. International collaborative research: significance of tick-borne hemoparasitic diseases to world animal health. Vet. Parasitol., 57: 1941.

Vahora, S.P., Patel, J.V., Parel, B.B., Patel, S.B., Umale, R.H. 2012. Seasonal incidence of haemoprotozoan disease in crossbred cattle and buffalo in Kaira and Anand district of Gujarat, India. Veter World, 5(4): 223-225.

Velusamy R, Rani N, Ponnudurai G, Harikrishnan TJ, Anna T, Arunachalam K, Senthilvel K and Anbarasi P (2014) Influence of season, age and breed on prevalence of haemoprotozoan diseases in cattle of Tamil Nadu, India, Veterinary World 7(8): 574-578.

Zafar, I., M. S. Sajid, A. Jabbar, Z. A. Rao and M. N. Khan (2006). Techniques in Parasitology. $1^{\text {st }}$ Ed., Higher Education Commission, Islamabad, Pakistan.

\section{How to cite this article:}

Shashi Kala, Bhawesh Gopal Deo and Nikee Kumari. 2018. Epidemiological Aspects of Theileriosis in Cattle in and around Patna, Bihar. Int.J.Curr.Microbiol.App.Sci. 7(03): 11831191. doi: https://doi.org/10.20546/ijcmas.2018.703.140 